\title{
JURISPRUDENCIA CONTENCIOSO-ADMINISTRATIVA
}

$351.95(46)(094.9)$

\section{Organización}

566. No es precisa disposición legislativa cuando la variación de los limites provinciales es consecuencia de la alteración de los municipios limitrofes.

«... y aunque el concepto de segregación resulta sin duda hipertrofiado al aplicarlo a una simple cuestión de deslinde, también se incide en desmesura al pretender que para decidirla haya imprescindible necesidad de acudir al más solemne y demorado de los dispositivos normativos, que lógicamente ha de reservarse para reorganizaciones o modificaciones precisas del ámbito territorial de las circunscripciones integrantes de la división en provincia del Estado español...»

(STS 25.3.1966. Sala 4. ${ }^{n}$ )

567. Un acto administrativo válido, pero no notificado, es un acto de eficacia demorada, y no totalmente ineficaz.

(STS 10.6.1966. Sala 4. ${ }^{\text {a) }}$

568. El servicio eléctrico constituye servicio público.

«... Tanto por la naturaleza objetiva de la materia, utilización de servicio eléctrico de $\mathrm{p}$ úblico interés, como de la función subjetiva de su adscripción a la vigilancia de orga- 
nismos estatales adecuados a tal servicio de trascendente interés a los efectos característicos de la intervención del poder público, en forma. de Administración....

(STS 6.7.1966. Sala 4.)

569. El carácter revisor de la jurisdicción no permite plantear cuestiones que no fueron antes sometidas a la Administración.

\&... y le veda el acceso a enjuiciar actos administrativos consentidos en vía gubernativa....

(STS 9.7.1966. Sala 5. ${ }^{a}$ )

\section{Personal}

570. Que la limitación temporal que fija el Reglamento de oposiciones $y$ concursos entre la publicación de la convocatoria y el comienzo de los ejercicios.

«... no es un plazo de caducidad ni motivo de invalidez de 10 actuado, ni contiene en su texto autorización para que las autoridades $u$ organismos que intervienen en la tramitación anulen o dispongan nuevas convocatorias, porque la pérdida de tiempo en la provisión de vacantes que busca evitar el precepto indicado, se aumentaría con el retroceso en el expediente y retraso consiguiente en la tramitación...)

(STS 27.6.1966. Sala 5.n)

571. La reiterada doctrina jurisprudencial sobre total independencia de los procedimentos penal ordinario $y$ sancionador administrativo.

«... que justifica no se supediten los términos a observar en éste a las determinaciones que se adopten en aquél, sin perjuicio de las incapacidades específicas que puedan derivarse de las sentencia condenatorias que se dieron..."

(STS 23.6.1966. Sala 5.,

572. Visada una plantilla de personal de un ayuntamiento por el Ministerio de la Gobernacion, Dirección General de Administración Local, no cabe recurrir contra las mismas.

«... en reposición, por no haber alterado ni modificado la plantilla en cuanto a la calificación y grado de la plaza que afecta al recurrente, haciendo saber a éste que puede reclamar ante la corporación municipal....

(STS 30.6.1966. Sala 5.a)

573. La fijación de los coeficientes multiplicadores del sueldo base, correspondientes a los distintos cuerpos, no aabe encuadrarla en actividad especifica distinta de la meramente administrativa.

«... puesto que se contrae a regular uno de los elementos determinantes de la retribución de los funcionarios civiles del Estado como es la fijación de los coeficientes multiplicadores del sueldo base...) (yy no la estructuración y régimen de retribuciones de los mismos...)

(STS 30.6.1966. Sala 5.a)

574. El reconocimiento del carácter normal de las pagas extraordinarias de Navidad y 18 de Julio.

«... hace que deban incluirse en la fijación del sueldo regulador para determinar los haberes pasivos de los 
funcionarios [y ello]...»; «... motiva el que hayan de ser satisfechas con cargo a la Mutualidad Nacional de Previsión de Administración Local...)

(STS 6.7:1966. Sala. 5.i)

575. Para determinar el haber de jubilación sólo son abonables los servicios prestados en propiedad $e$ interinos.

«...con destino de plantilla reglamentaria y con sueldo detallado en los presupuestos...)

(STS 30.9.1966. Sala 5.a)

576. Al denegar la Administración la excedencia voiuntaria a un profesor de la Orquesta Nacional.

«... no hizo otra cosa que ejercitar con plena justificación de causa la facultad que le está atribuída para apreciar discrecionalmente las necesidades del servicio...)

(STS 30.9.1966. Sala 6.")

\section{Procedimiento}

577. No existe acto confirmatorio porque los motivos que fundamentan la nueva petición no son idénticos.

«... a los que se alegaron en el primer expediente $\mathrm{ni}$ puede negarse que la ratio legis de la ley del suelo es más amplia y exigente que la antigua ley de Solares, tendente a servir una necesidad social apremiante que urbanísticamente exige un mejor aprovechamiento del suelo...)

(STS 22.1.1966. Sala 4.a)
578. Las cuestiones relacionadas con la validez del procedimiento son de preferente examen.

«... y dentro de ellos hay que conceder absoluta prioridad a las de competencia del órgano productor del acto como presupuesto esencial para su eficacia jurídica...»

(STS 25.4.1966. Sala 4. ${ }^{\text {) }}$

579. La Administración no viene obligada a mantener un criterio que estime equivocado después de advertido su error.

(STS 21.6.1966. Sala 5.3)

580. Una entidad particular de fines lucrativos carece de legitimación activa para impugnar. un decreto.

«... al no ostentar representación o defensa. de intereses generales o corporativos que para reconocerla exige el apartado b) del artículo 28 de la ley Contencioso-administrativa vigente....)

(STS 30.6.1966. Sala 4.a)

581. Las mercancias no tarifadas en alguna de las partidas de la Nomenclatura del Arancel de Aduanas.

«... deberán clasificarse en las partidas que comprenden los artículos que con ellas guarden mayor analogia, puesto que esa norma de analogía arbitrada por el Fisco para que las mercancias importadas aunque los aranceles no contengan, cuando se importen, concepto o partida para permitir el adeudo, aplicables, no actúa cuando existe una subpartida que con carácter residual fija los derechos correspondientes a las mercan- 
cías, no clasificadas o citadas en las demás partidas o subpartidas de los distintos capitulos y sus epigrafes...» (STS 4.7.1966. Sala 3.a)

582. Un improrrogable plazo de impugnación no puede entenderse dilatable por la acumulación gubernativa de actuaciones, acordada respecto de pretensiones idénticas de otro recurrente.

«... ya que la acumulación dejó subsistentes las circunstancias procesales peculiares individuales y separadas... $)$

(STS 9.7:1966. ISala 4.a)

583. No bastan las meras alteraciones de detalle para inscribir un objeto con nueva patente.

«... sino que a modificación ha de afectar a la esencia misma del objeto patentado....)

(STS 26.9.1966. Sala 4. ${ }^{\text {a) }}$

584. La ley no admite la subsanación de defectos sustanciales ocasionados en una via.

«... mediante las actuaciones practicadas en la otra, ya que el objeto de la revisión jurisdiccional son los actos contra los que se recurre, tal como se encuentran y pueden enjuiciarse al iniciarse la litis...)

(STS 28.9.1966. Sala 4. ${ }^{\mathrm{a}}$ )

585. El derecho a ejecutar la potestad discrecional no libera a la Administración de un comportamiento adecuado en la observancia del orden juridico.

\&... al deber estar sometida a 10 que doctrinalménte se califica de mo ralidad administrativa, que significa derivarse hacia una finalidad que no sea distinta a la determinada por il ordenamiento jurídico, discrecionalidad, reglada a su vez, que ha sido tenida en cuenta al dictarse la resolución recurrida...»

(STS 29.9.1966. Sala 3. ${ }^{\text {a) }}$

586. Ha de partirse en todo momento de la facultad discrecional de la Administración en la concesión de toda clase de servicio de transporte por carretera.

«... ya que tanto la declaración de la necesidad del servicio como la de su utilización constituye ejercicio de facultades discrecionales, si bien las mismas no suponen un entero arbitrio...l

(STS 29.9.1966. Sala 3.a)

587. Los acuerdos dictados por los jurados para determinar las bases tributarias de los contribuyentes no xueden ser impugnados en esta via jurisdiccional.

«... en lo que respecta a la cuestión de hecho, es decir a la fijación de las referidas bases, pues las decisiones que los repetidos jurados adopten lo son en conciencia e inspiradas en principios de equidad tributaria...»; "... lo cual es independiente para que el recurso pueda ser procedente, en los casos de errores in procedendo o cuando se deriva sobre cuestiones de derecho....»

(STS 4.10.1966. Sala 3.a) 


\section{I}

588. Importancia de los informes policiales en las sanciones por actos contrarios al orden puiblico.

«... y que en principio hay que concederles veracidad y fuerza probatoria al responder a una realidad de hecho, apreciada directamente por los agentes que acudieron a cortar el acto ilficito con detenciones y otras medidas preventivas tomadas contra los que fueron sorprendidos en flagrante actuación; todo ello como es naturail, salvo prueba en contrario que la parte interesada podrá aducir más tarde en descargo de las imputaciones que le fueren hechas..." (STS 5.10.1966. Sala 4.a)
589. El principio de imputación rigurosamente intraanual de los beneficios.

«... queria y quiere decir que no puede admitirse, a los fines de la obtención de la ventaja significada por una bonificación o deducción fiscal en el gravamen de los beneficios resultantes de la actividad social de un ejercicio económico, retrotraer o anticipar suma ailguna de las resultancias positivas de ejercicios distintos...)

(STS, 10.10.1966. Sala 3. ${ }^{a}$ )

ANTONIO DE JUAN ABAD

LUIS ENRIQUE DE LA VILLA 
